\title{
Self-Regulation of Middle School Students With Learning Disabilities During a Complex Project-Based Science Activity
}

\author{
Sheri Berkeley ${ }^{1}$, Anna Larsen ${ }^{1}$, Amanda Colburn ${ }^{2} \&$ Robert Yin ${ }^{3}$ \\ ${ }^{1}$ Division of Special Education and Disability Research, George Mason University, Fairfax, VA, USA \\ ${ }^{2}$ Division of Elementary, Literacy, and Secondary Education, George Mason University, Fairfax, VA, USA \\ ${ }^{3}$ COSMOS Corporation, Bethesda, MD, USA \\ Correspondence: Sheri Berkeley, Division of Special Education and disAbility Research, MSN1F2, George \\ Mason University, Fairfax, VA 22030, USA. E-mail: sberkele@gmu.edu
}

Received: March 29, 2019 Accepted: May 29, 2019 Online Published: June 18, 2019

doi:10.5539/jedp.v9n2p1 URL: http://doi.org/10.5539/jedp.v9n2p1

\begin{abstract}
Self-regulation is widely considered important for the academic success of students. Yet, there is limited research about how students self-regulate during complex, long-term learning tasks, such as the project-based learning activities that commonly occur as part of science classroom instruction. There is also less known about how atypical learners, including students with learning disabilities (LD), self-regulate academic tasks. The current multiple case study explores these gaps in the research base through an investigation of how middle school students with language-based LDs self-regulated their learning during a complex, science-based project — creation of computerized serious educational games (SEG) about renewable energy sources. Findings from the current study suggest that there is a relationship between attributions that students with LD make for their performance and their self-efficacy for learning, but only under specific conditions. The role of this relationship seems to diminish when a student poorly calibrates perception of ability relative to actual performance and when a student perceives the cost of effort to outweigh the benefit.
\end{abstract}

Keywords: attributions for learning, learning disability, science, self-efficacy, self-regulated learning, serious educational games

\section{Introduction}

With any project-based classroom assignment, a student can work on many different tasks to move towards completion of the project. Upon a cursory glance around the classroom, a teacher is likely to observe all students busy working on their projects; however, it is generally less obvious which students are on a path to success. Some students may jump right in without a plan and ultimately spend time spinning their wheels without completing the project or complete a project that contains little substantive content. Other students make a plan, strategically prioritizing tasks and setting goals for completing them. The result is generally a successful project that demonstrates application of content learning. This latter student would be considered to be a self-regulated learner.

Self-regulation refers to processes that learners use to activate and maintain cognitions, emotions, and behaviors to attain personal goals. Students are typically referred to as self-regulated learners if they are goal-directed, display strategic behaviors, and show high levels of self-awareness, self-reflection, and adaptation in their thinking (Zimmerman, 2000). The research literature has established self-regulated learning (SRL) processes to be highly predictive of students' achievement across virtually all academic skill areas and content domains, including reading, mathematics, writing, and science (e.g., Bembenutty, Cleary, \& Kitsantas, 2013; DeCorte, Mason, Depaepe, \& Verschaffel, 2011; Graham, Harris, \& Mason, 2005; Guthrie, Wigfield, \& VonSecker, 2000). As such, the degree to which students are capable of self-regulating their academic learning is an important area of study. In particular, self-regulation in project-based learning environments is needed as this has been less studied than self-regulation during discrete learning tasks (Schunk \& Zimmerman, 2003; Bernacki, Nokes-Malach, \& Aleven, 2015). This may be because it is difficult to investigate the feedback loop of student learning when the tasks to be completed for a project are complex and vary over time without inherent opportunity for repeated practice, such as the project-based learning activities that commonly occur as part of science classroom instruction. 


\subsection{Theoretical Perspectives on Self-Regulation}

A prominent perspective on SRL comes from Zimmerman's Self-Regulation Model (Zimmerman, 2000) which is grounded in Social Cognitive Theory. Within Zimmerman's model, SRL is theorized to occur within three cyclical phases that create a "feedback loop" that influences future self-regulation behaviors and ultimately learning outcomes. In the first phase, the forethought phase, learning goals are set and the learner strategically plans how to achieve these goals. In the next phase, the performance phase, the learner uses strategies that are most effective, resists distractions from the task, and monitors his own progress. In the final self-reflection phase, outcomes are evaluated and the learner reflects on progress made. Self-reactions in this phase are theorized to affect the first phase, creating the cyclical feedback loop which is characteristic of this model.

Motivation processes, such as self-efficacy, play a role in Zimmerman's model as well. Self-efficacy is regarded as the most essential process for motivating a person's behavior and it is strongly related to academic achievement (De Corte et al., 2011; DiBenedetto \& Zimmerman, 2010; Usher \& Pajares, 2006; Zimmerman, Bandura, \& Marinez-Pons, 1992). Self-efficacy refers to the capability beliefs of the student to accomplish a task under certain conditions (Bandura, 1993; Schunk \& Zimmerman, 1997). When faced with a challenging learning situation, students with well-developed self-efficacy tend to engage in self-regulatory behaviors such as applying cognitive strategies (Linnenbrink \& Pintrich, 2003). Students who are less self-efficacious might give up because the challenging activity is perceived as not within their ability. While research has shown that directing students' attention to the strategy aspects of learning can have positive effects on students' self-efficacy (Schunk, 1991), less is known about how they learn to do this for themselves. At least part of the answer may lie in an under-researched motivational aspect of SRL — causal attributions (Chapman \& Tunmer, 2003).

Causal attributions are one's judgments in achievement situations about the cause of success (e.g., "I succeeded because I worked hard and used strategies to help myself") or failure (e.g., "I failed because the teacher didn't help $m e ")$ (Shell, Colvin, \& Bruning, 1995; Weiner, 1985). According to attribution theory (Weiner, 1985), attributions to internal, stable and controllable factors are considered to be adaptive. Attribution research with students with learning disabilities (LD) have led to a more specified view that attributions for effortful strategy use are more adaptive for these students because such beliefs dispel "the inappropriate belief that effort always leads to success, but still helps to convey the idea that success is possible" (Linnenbrink \& Pintrich, 2002, p. 317). For this reason, adaptive attributions are theorized to be important for fostering effort and learning, particularly for students with LD (e.g., Carr et al., 1991). Based on collective findings from research on the causal attributions of students with LD (e.g., Donker, deBoer, Kostons, van Ewijk, \& van der Werf, 2014; Robertson, 2000), we posit that this motivational construct may play a larger role in SRL than has previously been suggested.

Students with LD more often attribute successes to external causes (e.g., luck) and failures to internal causes (e.g., lack of ability) compared with typically developing peers (Borkowski, Carr, Rellinger, \& Pressley, 1990; Tabassam \& Grainger, 2002). Further, adolescents with LD typically have a history of academic failure that results in the faulty belief that they have little control over their own academic achievement (Nelson \& Manset-Williamson, 2006). Because effort is critical for task persistence and self-regulation, findings suggesting that these students do not believe that their effort is a contributor to their learning is concerning. Further, it has implications for understanding the robustness of learning models that are based on typical learning, and as such, may take for granted important aspects of the self-regulation process that are crucial to learning and that may need to be explicitly taught to at-risk learners. Exploring the SRL characteristics of students with LD provides a unique opportunity to better understand how and why self-regulation breaks down, how this affects learning, and where self-regulation supports may be most needed for students who struggle to learn.

\subsection{The Current Investigation}

The current study explored how middle school students with language-based LDs self-regulated their learning during a complex science project. Specifically, the project required students to create their own computerized serious educational games (SEG) about renewable energy sources using a software platform developed for the project. This learning medium was selected because there is growing research support for engaging and motivating students to learn through this medium (Cheng \& Annetta, 2012; Connolly, Boyle, MacArthur, Hainey, \& Boyle, 2012; Giannakos, 2013; Marino Israel, Beecher, \& Basham, 2013), and therefore, was likely to be a desired learning activity for the targeted sample.

Within the self-regulation cycle, particular attention was given to how attributions for effort (including strategy use) and subsequent self-efficacy ratings functioned within the cyclical feedback loop. We theorized that effort attributions would correspond with either high self-efficacy ratings for any given task or self-efficacy ratings that increased after repeated opportunities to practice the task. This scenario would be indicative of a functioning 
feedback loop and would be expected to foster continued learning. We also theorized that attributions that did not include effort would correspond to low self-efficacy ratings or inconsistent ratings that were not consistent with observed performance. This scenario would be indicative of a breakdown in the feedback loop that would be expected to impede future learning efforts.

\section{Method}

\subsection{Participants}

The study took place in a large suburban school district on the East Coast of the United States. Three $6^{\text {th }}$ grade students (one male and two female) met screening criteria for this exploratory investigation. All students were identified by the school district as meeting special education eligibility criteria for a specific LD in a language-based area — speech/language, reading, and/or written expression. All participating students had IQs classified as "normal" (range 85-103) and scored below the $25^{\text {th }}$ percentile on both the Gates MacGinite Reading Test (MacGinitie, MacGinitie, Maria, \& Dreyer, 2000; range $7^{\text {th }} \%$ tile to $21^{\text {st }} \%$ tile) and Test of Word Reading Efficiency (Torgesen, Wagner, \& Rashotte, 2012; range $<1 \%$ tile to $25^{\text {th }} \%$ tile) that was administered by the researchers prior to the start of the investigation.

\subsection{Project Activities}

\subsubsection{Project-Based Science Learning Activities}

Prior to beginning the project activities, students received traditional science instruction about renewable energy. This instruction was intended to activate prior knowledge about energy sources, to pique interest in learning more about the topic, and to help students generate initial ideas for the SEGs they would create.

First, students were taught how to make a plan for their SEG design and how to create a basic plot for their game using the same story map they were familiar with from the language arts curriculum. Games typically contain multiple levels of increasing difficulty; initial student planning focused only on the first level of the game (level 1). Students utilized custom planning notes to help them think through all of the aspects of their SEG prior to beginning to build. Then, students completed two activities that helped them evaluate their progress: (a) a self-evaluation checklist of the critical SEG components, and (b) a think-aloud of their game design process.

Next, students were taught how to create their own SEG using a custom gaming platform developed specifically for the project. As students used the platform, they needed to adjust their original plan, either because they discovered flaws to their original planning or because they had additional ideas that they wanted to incorporate into their game. Once students completed game level 1, they once again completed a self-evaluation checklist and think-aloud to help them reflect on their progress. At this point, students were given the option either to build a second game level (level 2) or to continue to make improvements to level 1.

\subsubsection{Goal Setting and Reflection}

Prior to beginning daily independent work, students were taught why goals help people obtain desired outcomes and how to set them. Each work session began with students setting a goal for that work session and ended with students reflecting on their progress for that day.

\subsection{Data Sources and Procedures}

A variety of data sources were used to understand the self-regulation process of each student during each work session. Students recorded their daily goals (including ratings of self-efficacy) and reflection of progress (including attributions for performance) on goal setting and reflection logs. To gain richer insight into each student's SRL process, a researcher interviewed one targeted student during the goal setting and reflection portion of each work session to probe for explanations of log responses. Additionally, the targeted student was observed using screen share software that enabled the researcher to monitor the work session in real time. This helped researchers gauge the accuracy of student self-report of their performance.

A separate trained observer documented all other activities within each work session. Field notes were taken electronically to capture interactions with the instructor and among students in the work group. Specific times were noted when student verbalizations related to attributions, self-efficacy, or other evidence of self-regulation occurred so that this portion of the observation could be transcribed verbatim. In an adjacent column to the factual observation notes, notations of conjecture, interpretation, comments, and emerging themes were recorded.

\subsection{Data Analysis}

A multiple case study design was utilized to allow for replication across cases (Yin, 2014). Individual students served as cases as we wanted to understand the SRL efforts of the individual student who has unique experiences 
and abilities. Data collected were analyzed using a time series approach. First, student-created goals were analyzed to identify the boundaries for each learning task within each game level. This was a necessary step in the process because attributions for explaining performance on a task could only be reasonably inferred to correspond to self-efficacy when the student worked on the same type of task.

Next, to determine the nature of the relationship between attributions and self-efficacy ratings, student responses to questions related to the reasons for their performance (i.e., attributions) were classified as (a) effort attributions-if the explanation related to effort, including effort to use cognitive learning strategies, (b) other attributions-if the explanation did not meet the criteria for strategic cognitive effort (e.g., attention management, teacher assistance), or (c) none - if the student was unable to provide any explanation. A visual display of these data was then created by juxtaposing student attributions for performance and subsequent self-efficacy ratings.

Finally, data not included in the primary analysis (e.g., general observations, teacher notes, student work) were used to contextualize findings and provide evidence of a cyclical SRL feedback loop or lack thereof. After analysis of each individual case was completed, researchers then conducted a cross-case analysis of findings for each case to induct an explanation of the relationships that emerged between the targeted constructs.

\section{Results}

Findings are presented for each of the three cases: Mario, Emma, and Sharone. This is followed by a description of findings from cross-case analysis.

\subsection{Mario}

Mario was an 11-year-old, Caucasian, boy. In an interview prior to the project, he rated science as a four on a scale from 1 to 10, even though he reported that he was "getting an A in science class" and thought he did well on the state science test he took the previous year. He also reported that he likes video games and that he played them "like an hour every day"; however, the games he noted (basketball, racing) are more for entertainment than for education.

Mario received 75 minutes of special education services each week in the areas of speech articulation and written expression. Despite average math abilities $\left(58^{\text {th }}\right.$ percentile on the Test of Mathematical Abilities, TOMA) and a relatively higher vocabulary $\left(27^{\text {th }}\right.$ percentile on the GMRT), Mario's reading comprehension was quite impaired ( $7^{\text {th }}$ percentile on the GMRT). On a test of energy concepts administered after science mini-lessons, Mario correctly answered $89 \%$ of items related to vocabulary knowledge targeted by the instructor and demonstrated understanding of many of the concepts in his short answer responses. For example, one of his short answer responses for a question on the advantages for solar energy was, "It will never run out and will not cause pollution."

Field notes from the instructor indicate that Mario often answered questions that reflected his understanding of the vocabulary and content relative to the other participating students: "Mario often had prior knowledge of vocabulary or other content... he was frequently the first student to answer a question posed to the class or to offer a personal experience or thought about a practical application of the content." This led the instructor to mistakenly believe he had greater overall competence in reading than may have actually been the case-- "Mario appeared to be the fastest reader with the highest comprehension, but he had difficulty staying focused and on task." In addition, the instructor sometimes mistook his reluctance to attempt revisions - particularly those that involved reading and writing-- as a behavioral desire to do as little as possible rather than as being related to an area significantly impacted by his disability. This assumption is illustrated by an instructor comment about Mario's work ethic: "What appeared to be caution was in fact indicative of a minimalist approach to learning activities and a narrow attention span for material not of immediate interest to Mario."

\subsubsection{Mario's SRL}

Overall, Mario exhibited a typical SRL cycle while creating game level 1, but his motivation waned toward the end of the project. He stopped attempting to self-regulate his learning altogether by the time he began working on game level 2. See Table 1. 
Table 1. Mario's Attributions, Self-Efficacy, And SRL Description within Each Game Level

\begin{tabular}{|c|c|c|}
\hline Task & Attribution & SE \\
\hline \multirow{5}{*}{$\begin{array}{l}\text { Task 1: Planning } \\
\text { game level } 1\end{array}$} & $\mathrm{n} / \mathrm{a}$ & 50 \\
\hline & Other-"thinking a lot", & 50 \\
\hline & Effort-"finished [goal]", & 75 \\
\hline & Effort-"worked hard" & 90 \\
\hline & Effort-"finished goal" & $\mathrm{n} / \mathrm{a}$ \\
\hline \multirow{4}{*}{$\begin{array}{l}\text { Task 2: Planning } \\
\text { game level } 1\end{array}$} & $\mathrm{n} / \mathrm{a}$ & 90 \\
\hline & Other-checking work* & 80 \\
\hline & Effort-"finished [goal] \& worked hard" & 90 \\
\hline & Effort-"finished [goal]", & $\mathrm{n} / \mathrm{a}$ \\
\hline \multirow{9}{*}{$\begin{array}{l}\text { Task 3: Building } \\
\text { game level } 1\end{array}$} & $\mathrm{n} / \mathrm{a}$ & 70 \\
\hline & Task difficulty_-"hard"* & 70 \\
\hline & None* & 90 \\
\hline & Effort-"finished [goal]" & $\mathrm{n} / \mathrm{a}$ \\
\hline & [12 day winter break] & \\
\hline & $\mathrm{n} / \mathrm{a}$ & 75 \\
\hline & Effort-"finished goal" & 80 \\
\hline & Effort-"finished [goal]", & 100 \\
\hline & Effort-"finished [goal]", & $\mathrm{n} / \mathrm{a}$ \\
\hline \multirow{4}{*}{$\begin{array}{l}\text { Task 4: Building } \\
\text { game level } 1\end{array}$} & $\mathrm{n} / \mathrm{a}$ & 90 \\
\hline & Effort-"finished [goal]", & 90 \\
\hline & None* & 100 \\
\hline & Task difficulty-“not that much" & $\mathrm{n} / \mathrm{a}$ \\
\hline \multirow{6}{*}{ Task 5: Planning \& building game level 2} & $\mathrm{n} / \mathrm{a}$ & 90 \\
\hline & None & 95 \\
\hline & None* & 90 \\
\hline & Effort-“finished [goal]"+ Task difficulty-"easy" & 95 \\
\hline & None & 90 \\
\hline & None & $\mathrm{n} / \mathrm{a}$ \\
\hline
\end{tabular}

*Mario did not meet his goal this day.

The goals that Mario set for himself suggest that he conceptualized game planning and game building holistically as singular tasks that needed to first be completed and then refined. For instance, a goal during the building phase was to "finish scene 1, then start scene 2." Initially, the researchers wondered whether Mario's goals were too broad for him to effectively evaluate his performance at the end of the work session, so in an interview, he was asked to elaborate on the goal that he wrote for one of the sessions.

Interviewer: What will you work on specifically today?

Mario: Probably scene one and characters and putting stuff where it needs to go.

Interviewer: So the characters?

Mario: (shakes head yes) And the birds eye view.

Interviewer: Anything else?

Mario: Uh no... oh the title

Mario: ... and the opening scene. 
Although his goals appeared broad, his verbal explanation showed that, to him, they actually referred to specific, concrete steps that corresponded to what he had planned. Mario's next goals indicate that his thinking was influenced by external feedback sources. For example, after completing a game self-evaluation checklist provided by the researchers, he began working toward completion of a new task ("to make improvements on the no's I filled out" [referring to the checklist]). In addition, in interviews following the next few work sessions, Mario attributed his progress to using these resources to help him set his next goals ("I looked at the chart [checklist] to see what I needed to work on").

While creating game level 1, Mario attributed successful performance primarily to effort for each task. A typical response was "I worked hard and tried to finish it." He also often attributed his progress to his focus on self-set goals, for example, "because I finished my goal" or "because I finished my scene 3 [his goal for the day]." Because setting goals was one of the researcher-taught cognitive learning strategies, responses related to goal setting or attainment were categorized as effort attributions. During this part of the project, his self-efficacy ratings were lowest on days that he initiated new tasks, and his effort attributions corresponded to an increase in self-efficacy for both planning tasks. This is the typical relationship between these two constructs within Zimmerman's Self-Regulation Theory.

As the project progressed, Mario's effort attributions related solely to goal setting. Additionally, explanations for performance that were out of his control, sometimes referred to as maladaptive attributions, began to emerge as well. These other attributions included external assistance (e.g., "teacher help") and task difficulty (e.g., "I thought I would finish, but it was hard to rotate [a game object]"). His attribution for external assistance corresponded to a low self-efficacy rating and his attribution to task difficulty was related to high self-efficacy. The latter high self-efficacy rating may be because although he found the identified task difficult, he eventually succeeded in completing it.

Mario's motivation visibly declined toward the end of the project, and eventually, he refused to work on game building altogether. In some respects, this was surprising because he had opted to create a level 2 for his game and he came up with a creative concept related to renewable energy about which he seemed excited initially. To explore this further, we looked through the data sources to understand what else was occurring during that timeframe. His goals reflected his intention to skip the planning for level 2 and instead immediately begin building. The researchers queried Mario during his interview to try to understand why he abandoned the supports and strategies that had helped him self-regulate his progress when making game level 1.

Interviewer: If you're not using your binder [that contained scaffolded planning supports], what are you going to use to help you keep track [of what to work on]?

Mario: My brain

Interviewer: Your brain. What is it about the binder that you don't want to use?

Mario: I don't know. It's a lot of work.

Interviewer: What is a lot of work?

Mario: Filling out the pages.

Interviewer: Do you mean the writing part?

Mario: Yeah.

Interviewer: So, the writing is a lot of work? What if you could plan this on the computer? Like instead of hand writing it what if you could type it out. How would you feel about it?

Mario: It would still take a lot of time.

Interviewer: Would you be more likely to do it if it was planning on the computer?

\section{Mario: No}

Interviewer: Ok. So it's not the handwriting.

Mario: Yeah. It's just like doing it.

Mario's responses suggest that he did not believe that the outcome would be worth the effort he would be required to expend. Not surprisingly, because Mario did not employ the planning strategies that he learned when making level 1, he struggled to execute his idea and became fatigued working on level 2. Ultimately, he abandoned his game altogether. 


\subsection{Emma}

Emma was a 12-year-old, Caucasian, girl. In an interview prior to the project, she rated science as a 4 or 5 (on a scale of 1 to 10) and indicated that "science is really hard" and "a little bit boring." She shared that her dad plays video games every day, but that she does not. However, she mentioned that she occasionally plays B-cube, a maze game, for fun.

Emma received 930 minutes of special education services each week in the areas of reading (phonics, fluency, and comprehension) and written expression. Emma displayed very low academic skills in both math $\left(13^{\text {th }}\right.$ percentile on the TOMA) and reading comprehension $\left(10^{\text {th }}\right.$ percentile on the GMRT) with a particular weakness in vocabulary development ( $1^{\text {st }}$ percentile on the vocabulary subtest of the GMRT). On a test of energy concepts administered after science mini-lessons, Emma displayed a limited understanding of vocabulary, answering only $33 \%$ of items correctly. Emma's short answers showed that she may have understood some of the material, but was not able to explain her reasoning. For example, she indicated that an advantage of wind energy is "because you can get it a lot." This may mean that in certain locations, there is a lot of wind that could be harnessed, but Emma did not provide this explanation. Additionally, she provided inconsistent answers across items, which showed her lack of clear understanding of many of the important concepts. For example, in response to one item, she indicated that an advantage of fossil fuels is "we can rely on it to give us energy." However, on another item, she described a disadvantage of fossil fuels as "it might not give all the energy you need." This may show that she understands what reliable means for an energy source, but does not know whether fossil fuels in particular are reliable.

Instructor reflection notes indicate that Emma had many ideas for her game ("at one point asking the instructor if it was possible for her game to have fifteen questions and multiple levels" rather than the instructor suggested three questions at each game level). Instructor field notes also suggest that she had difficulty refining and organizing those ideas into a coherent framework ("she also created and named a multitude of characters, most of which did not have any role in the actual game plan"). Although Emma used numerous resources during the process (e.g., articles about renewable energy, her game planning notes), this did not translate to conceptually accurate content being placed in her finished game ("much of the environment and content of her game did not match well with her plans"). A partial explanation may lie in the fact that Emma was absent on numerous occasions during both science instruction lessons and the initial game planning. Although she was always eager to catch up and was not hesitant to engage with the rest of the group, these absences may have impeded her broad conceptual understanding of the project. To illustrate, the instructor commented, "Emma chose to build her own game environment, and named it 'Emma's Ice Cream Town'-- a baffling choice considering there was no connection there to the intended renewable energy theme for the game."

\subsubsection{Emma's SRL}

As shown in Table 2, Emma initially exhibited a typical SRL cycle while planning level 1. As more independent cognitive effort was required, however, it appears that Emma experienced fatigue and a decrease in motivation and eventually abandoned attempts to self-regulate.

Table 2. Emma's Attributions, Self-Efficacy, And SRL Description within Each Game Level

\begin{tabular}{lll}
\hline Task & Attribution & SE \\
\hline & n/a & 80 \\
Task 1: Planning & None & 89 \\
game level 1 & Effort* + Behavior- "on task and I wasn't talking” & 99 \\
& None** & 100 \\
& Effort- "worked hard” & n/a \\
\hline & n/a & 85 \\
Task 2: Planning & Effort- "worked hard” & 100 \\
game level 1 & Effort* + Behavior- "on task” & 100 \\
& Effort* & $\mathrm{n} / \mathrm{a}$ \\
\hline
\end{tabular}




\begin{tabular}{|c|c|c|}
\hline \multirow{5}{*}{$\begin{array}{l}\text { Task 3: Building } \\
\text { game level } 1\end{array}$} & $\mathrm{n} / \mathrm{a}$ & 77 \\
\hline & Effort* + Behavior- "didn't talk" & 95 \\
\hline & Effort* + Behavior- "on task" & 80 \\
\hline & None & 88 \\
\hline & Behavior-"on task" & $\mathrm{n} / \mathrm{a}$ \\
\hline \multirow{4}{*}{$\begin{array}{l}\text { Task 4: Building } \\
\text { game level } 1\end{array}$} & $\mathrm{n} / \mathrm{a}$ & 90 \\
\hline & Effort + Behavior-"on task" & 90 \\
\hline & Behavior-"on task" & 100 \\
\hline & None** & $\mathrm{n} / \mathrm{a}$ \\
\hline \multirow{2}{*}{$\begin{array}{l}\text { Task 5: Planning } \\
\text { game level } 2\end{array}$} & $\mathrm{n} / \mathrm{a}$ & 80 \\
\hline & $\begin{array}{l}\text { Effort- "worked hard" + Behavior- "on task \& } \\
\text { not talking", }\end{array}$ & $\mathrm{n} / \mathrm{a}$ \\
\hline \multirow{5}{*}{$\begin{array}{l}\text { Task 5: Building } \\
\text { game level } 2\end{array}$} & $\mathrm{n} / \mathrm{a}$ & 80 \\
\hline & Behavior- "on task" & 80 \\
\hline & Behavior**_"on task” & 95 \\
\hline & Behavior-"wasn't talking” & 95 \\
\hline & Behavior**_"on task” & $\mathrm{n} / \mathrm{a}$ \\
\hline
\end{tabular}

*states that she will start, or has started, the next logical task because she has met or made progress toward her goal (a taught strategy).

**student goal was extremely vague, so student was not able to evaluate progress toward it.

Overall, Emma set goals loosely around separate tasks related to planning her game (e.g., completing a story map for her game plot or embedding science content by writing questions and hints for scenes within her game) and general game construction (e.g., "put stuff in my town," "doing scene 2") or game refinement (e.g., "fix up stuff"). This suggests she conceptualized the process as involving separate and discrete tasks.

Until the end of the project, Emma most frequently attributed effort (e.g., "because I worked hard"), self-management of her behavior (e.g., "I wasn't talking and stayed on task") or a combination of the two as the explanation for her performance. Her continued attributions to behavior self-management were surprising because the workspace was quiet with limited distractions. Occasionally, Emma set a goal so vague that she could not evaluate her progress toward it and then understandably did not have an explanation for her performance. Emma's self-efficacy ratings were lowest on days she initiated new task and her self-efficacy ratings increased over time as she successfully made progress on a task.

During the work sessions, however, Emma did not approach her self-identified tasks linearly, but instead vacillated in her efforts. This often seemed to undermine the efficiency of her progress. She was also disorganized in her notations, which made it difficult for her both to track her progress and to locate information when needed later in the process. Despite this, there was evidence that she was self-regulating her learning of game design concepts. The following conversation illustrates her general understanding of the game development process and that she was accurately self-evaluating her performance on this particular task.

Interviewer: Can you tell me what goal you are going to work on today?

Emma: I need to do my hints for my game.

Interviewer: How did you decide that's what you need to work on?

Emma: Um, because I did my questions... I was working on my scenes and I realized I don't have any hints [to help a player learn] if someone gets it [the question] wrong.

Her responses to the interviewer's queries indicated she understood the logical order of steps and by following the steps, she was able to determine a step she had missed (e.g., providing hints for the player) through accurate self-evaluation.

By the time Emma began working on level 2, she almost exclusively made attributions to her efforts to manage her own behavior (but not to cognitive effort). Yet, observation notes indicate that she was not actually productively on 
task, but rather, she was often disengaged and did not actually work toward the goals that she set. Regardless, her self-efficacy ratings increased from low to high across these work sessions. It should be noted that this increase in self-efficacy occurred immediately following an interview with the researcher, and this external feedback and positive reinforcement may have influenced her self-perceived ability to achieve her goal. To better understand what was happening in the learning context that may have played a role in changes in Emma's self-reported attributions and accuracy of self-perceptions of performance, we looked more closely at the data for evidence of how she was attempting to self-regulate.

Emma's affect and comments while creating level 2 suggest that she was losing motivation for the project. She produced very little during this time frame despite setting appropriate goals that were representative of the successful approach she took for level 1. At one point, Emma abandoned planning efforts to conceptualize her game and moved on to building her game on the computer. When encouraged by the teacher to continue planning level 2 as she had done for level 1, Emma responded "I don't want to [plan] because it is too much work." Her decision to abandon her planning material caused Emma to struggle with building level 2. Instead of spending her time using the planning skills taught during the intervention, her decision to abandon planning impacted her ability to accurately self-reflect as she struggled to consistently work on the same task.

To try to better understand the precursors to her decision to abandon effort and strategies to self-regulate level 2 creation, we looked more closely at events that had preceded. We observed that as she moved into a more advanced stage of the project, she had begun to struggle with self-evaluation of her performance. This excerpt from a conversation with another student after "play-testing" her game illustrates:

Mario: Why is it destroying stuff when nothing happened?

Emma: I don't know.

Mario: Why is it destroying the good stuff [renewable energy sources]?

Emma: I don't know. I just made it disappear.

Mario: Didn't it say go to your last quiz?

Emma: Ohhh yea...

Mario: Yea. There's nowhere to go next.

Emma: Okay. I'll work on that.

Although Mario pointed out to Emma spaces where her game could be improved and she said that she would work on making those improvements, she was not able to do so. In a future play test with another student, the same issue was noted.

Sharone: Why is all the good stuff disappearing?

Emma: I have no idea! I just picked random stuff.

Emma's inability to self-evaluate after feedback from her peers and incorporate changes to her game seemed to be impacted by the amount of effort she perceived the revision process to take.

\subsection{Sharone}

Sharone was an 11-year-old, African American, girl. In an interview prior to the project, she rated science as 5 out of 10 because she said "It's not really my favorite thing." She did indicate that she plays games every day on her kindle and that she particularly likes Crossy Road, a game where a chicken tries to navigate crossing the road (requiring visual special awareness and motor coordination from the player).

Sharone received 570 minutes of special education services each week in the areas of reading (phonics and comprehension) and written expression. Sharone scored below the $25^{\text {th }}$ percentile on both subtests of the GMRT ( $23^{\text {rd }}$ percentile in vocabulary, $21^{\text {st }}$ percentile in comprehension) and at the $3^{\text {rd }}$ percentile in math according to the TOMA. On a test of energy concepts administered after science mini-lessons, Sharone correctly answered $89 \%$ of items related to vocabulary knowledge. However, her short answer responses suggest that she may have only had a surface understanding of the related concepts. In her short answer responses, Sharone was often not able to explain what she was thinking or seemed confused about what the question was asking. For example, she described a disadvantage of solar energy as the "earth might get dusty" and a disadvantage for wind energy as "having to go to a warmer place." In some cases, her answers lacked clarity, which made it difficult to evaluate the depth of her understanding. For example, when asked about disadvantages of fossil fuels, she indicated "it could pollute the earth with gas." She may have been referring to the gas carbon dioxide, which is a pollutant, or she could have meant that burning gasoline causes pollution, or she could have literally meant that gasoline pollutes the earth. 
Field notes indicate that the instructor perceived Sharone to be highly engaged during group work, but that she would often struggle to remain on task and make progress during independent work. The instructor also noted that she had a high threshold for incorrect responses before becoming frustrated or giving up; however, getting started for the day was generally a challenge for Sharone ("She entered class every day ready to work and with many ideas; however, it always took Sharone longer than the others to settle down, arrange her work space, clarify her thinking, and actually begin her work for the day"). This may be part of the reason that Sharone needed more time than the other students to complete tasks throughout the project.

\subsubsection{Sharone's SRL}

Sharone's efforts to self-regulate her learning did not appear to be productive until the very end of the project and improvements seemed to be in response to feedback from one of the researchers during an interview rather from her own self-evaluation of her performance. Although her behavior at the end of the project suggested that she was beginning to self-regulate effectively, the project ended before this could be confirmed. See Table 3.

Table 3. Sharone's Attributions, Self-Efficacy, and SRL Description within Each Game Level

\begin{tabular}{|c|c|c|}
\hline Task & Attribution & SE \\
\hline \multirow{8}{*}{$\begin{array}{l}\text { Task 1: Planning } \\
\text { game level } 1\end{array}$} & $\mathrm{n} / \mathrm{a}$ & 80 \\
\hline & Effort- "used resources" & 100 \\
\hline & Other- "took my time \& thought" & 100 \\
\hline & None & 100 \\
\hline & None & 100 \\
\hline & Effort- "I had a plan" & 100 \\
\hline & Behavior-"on task" & 100 \\
\hline & Effort- "used resources" + Behavior- "on task" & $\mathrm{n} / \mathrm{a}$ \\
\hline \multirow{3}{*}{$\begin{array}{l}\text { Task 2: Planning } \\
\text { game level } 1\end{array}$} & $\mathrm{n} / \mathrm{a}$ & 89 \\
\hline & Effort- "I had it planned" & 89 \\
\hline & Behavior-"on task" & $\mathrm{n} / \mathrm{a}$ \\
\hline \multirow{4}{*}{$\begin{array}{l}\text { Task 3: Building } \\
\text { game level } 1\end{array}$} & $\mathrm{n} / \mathrm{a}$ & 100 \\
\hline & [12 day winter break] & \\
\hline & Behavior-"on task" & 89 \\
\hline & Behavior-"took my time \& on task" & $\mathrm{n} / \mathrm{a}$ \\
\hline \multirow{14}{*}{$\begin{array}{l}\text { Task 4: Building } \\
\text { game level } 1\end{array}$} & $\mathrm{n} / \mathrm{a}$ & 100 \\
\hline & Behavior- "on task" & 100 \\
\hline & Behavior- "on task" & 100 \\
\hline & Effort* + Behavior-"on task" & 100 \\
\hline & Behavior-"on task" & 100 \\
\hline & Behavior-"on task" & 100 \\
\hline & Behavior-"on task" & 100 \\
\hline & Behavior-"on task" & 100 \\
\hline & [Game Interview] & \\
\hline & Effort* + Behavior-"on task" & 88 \\
\hline & Behavior-"on task" & 88 \\
\hline & Effort* & 87 \\
\hline & Effort* + Behavior-"on task" & 88 \\
\hline & Behavior-"on task" & $\mathrm{n} / \mathrm{a}$ \\
\hline
\end{tabular}

*restates her goal (setting goals was a strategy taught to students) as the reason she met/didn't meet her goal rather than providing an explanation for why. 
Sharone appeared to conceptualize game building as two distinct tasks that needed to be completed: building her game (e.g., "finish scene 1") and improving her game ("finish my game and testing my game and see how it's working;" "fix my introduction and also fix my question"). Yet, researchers observed that Sharone skipped the elements of the planning process that required her to conceptualize her overall game plot and instead she jumped right into setting goals to plan her game events using the scaffolded planning resources (e.g., "finishing her scene one planning;" "finish up bird's eye view [setting];" "finish completing my question for my scene"). She then returned to goals related to the overarching concept of her game (e.g., "opening scene planning") and struggled to retrofit a coherent plot to already completed work.

Sharone made inconsistent attributions throughout her tasks across all learning events. Although she occasionally made effort attributions for goal setting, more frequently her attributions were related to other explanations for her performance, such as behavior self-management (e.g., "I was on-task; " I didn't talk"). When asked what strategies she used that day, she often reported using appropriate strategies, but rarely attributed strategy use as an explanation for her performance. Sharone initially was consistent in attributing her performance to both effort (most frequently goal setting) and behavior self-management; however, as she began building, she inconsistently attributed her performance to effort.

Additionally, it appears that there was a large disconnect between Sharone's perceptions and actual events. Sharone consistently reported high self-efficacy (100 on a scale of 1 to 100). However, during both planning and building stages, instructors' observation of her actual performance did not align with her high self-efficacy ratings. This is an indicator that her self-efficacy ratings were overestimated and that her self-reports were poorly calibrated.

When Sharone determined that her level 1 was finished, a researcher interviewed her about it. In this interview, the researcher asked Sharone to think aloud while playing her game to explain her thinking about science concepts and game design features. During the interview, Sharone used post-it notes from her instructional binder to take extensive notes about things she would want to change based on questions she could not answer clearly for the researcher or made notes on her game checklist about things she would like to change. Following is an excerpt from discussion around one of the questions embedded within her game.

Sharone: [talking aloud while playing her game] So it says, "What device was powered by the wind that produces motion to generate electricity."

Researcher: [reading answer choices] "wind turbine, solar energy, solar cells, and wind farms." You know, I'm confused on this one, because I'm thinking, "Wind turbine, yes!" But, wind farm [is correct], too.

Sharone: Hmm... [thinking]

Researcher: Does it [the question] really have one, and only one, answer?

Sharone: Let me try this one... [Starts playing the game by purposefully choosing an incorrect answer and navigating to the hint in the game.]

Researcher: [reads hint aloud] "It generates wind"... But, you know, a wind turbine and a wind farm both generate wind. Don't they?

Sharone: Um, yeah! So, I should go back on that and make sure that question is [writes note on her game checklist to fix that question]. Okay! Make that question!

After completing the interview, Sharone decided to continue building game level 1 rather than moving on to game level 2.

Researcher: Are you happy with your game? What would you do differently?

Sharone: Um, go back and review everything and make sure everything makes sense.

Researcher: So, what are you going to spend the rest of today doing? Are you going to go back to this level or are you going to go to the new level? If you are planning, what's your plan, do you think?

Rowan: Maybe, like, go back to do this level [level 1] and like, make sure my hints make sense and the questions, before I go onto another level.

She then continued to set goals related to improving level 1. Her reported attributions included a greater focus on effort (goal setting in particular), and her self-efficacy dropped and was more realistic relative to her observed performance (87-88 out of 100). Because the project ended, it is unclear whether Sharone's self-efficacy would have increased if she had been given more time. This suggests that the process of reflecting on her game with the assistance of an adult helped her to more accurately self-evaluate her performance. 


\section{Cross-Case Analysis and Discussion}

Cross-case analysis suggests that attributions influenced self-efficacy for students with LD and contributed to a functioning feedback loop. However, this influence on the feedback loop seems to diminish when a student poorly calibrated perceptions of ability relative to actual performance and when a student perceived the cost of effort to outweigh the benefit. Further, a breakdown in self-regulated learning, referred to as self-regulation failure, was observed in all participating students at some point in the project. See Table 4.

Table 4. Cross-case Analysis Summaries

Summary of Mario's Findings for Cross-case Analysis

\section{Game level 1:}

- Mario predominantly attributed performance to effort, including goal setting. He often focused on "finishing" his goal rather completing the goal well. His self-reported self-efficacy ratings were similar for game planning tasks (1.1, 2.1). That is, his ratings were lowest on days when he initiated new tasks and increased over time. These data combined with researcher observation reflect a typical SRL cycle. [effort attributions correspond to self-efficacy].

- Conversely, his attributions were more varied and his self-efficacy ratings were consistently high for refinement goals $(1.2,2.2)$. Further, researcher observations of his performance contradicted his perception of efficacy [poor calibration], revealed a visible decline in motivation, and suggested that he valued completion over quality of work [low standards]. These combined data suggest a diminished feedback loop.

\section{Game level 2:}

- Mario predominantly made no attributions to explain his performance despite consistently high self-efficacy ratings. Observations reflected self-regulation failure due to perceived effort required [cost outweighs benefit].

Summary of Emma's Findings for Cross-case Analysis

Game level 1:

- Emma predominantly attributes performance to effort and/or self-management of behavior. Her self-efficacy ratings were lowest on days she initiated new tasks and increased over time. Observation reveals difficulty with self-monitoring [inaccurate self-evaluation] and taking corrective feedback [adjusting behavior]. These combined data reflect a typical SRL cycle [effort attributions correspond to self-efficacy]

\section{Game level 2:}

- Emma predominantly attributes performance to behavior. Like with level 1, her ratings were lowest on days she initiated new tasks and increased over time. However, observations indicate she was not actually on task and produced very little [poor calibration]. These combined data reflect self-regulation failure due to perceived effort required [cost outweighs benefit].

\section{Summary of Sharone's Findings for Cross-case Analysis}

\section{Game level 1:}

- Sharone predominantly attributes performance to effort and/or self-management of behavior. Her self-efficacy ratings were consistently high (100 on 1 to 100 scale), but inconsistent with observed performance so her self-efficacy ratings were likely overestimated [poor calibration]. Evidence of a typical SRL cycle was not observed, but rather, observations revealed difficulty with self-monitoring of performance [inaccurate self-evaluation].

- During her level 1 game interview, Sharone received scaffolded support in self-evaluating the quality of her game. After this interview, her attributions shifted to a mixture of effort to goals (rather than general "effort") in addition to self-management of behavior. Her self-efficacy ratings were lower, but became consistent with researcher observations of her performance. She also showed evidence of improved self-evaluation [emerging evidence of SRL cycle].

\subsection{Calibration}

Student effort attributions corresponded with self-efficacy ratings that were high or that increased over time, but only when student self-efficacy ratings were reasonably calibrated with observed student performance. Two students accurately calibrated their performance when developing game level 1, but as the project progressed, they 
fatigued and their motivation deteriorated. By the time they started working on level 2, these two students displayed markedly reduced effort and their self-efficacy ratings were not consistent with the researchers' observations of their performance. Both Mario and Emma had high self-efficacy beliefs for tasks or had increasing trajectories for self-efficacy beliefs for self-identified tasks over time. This was related to the successful attainment of their personal goals. When these students moved into level 2, however, they both decided to abandon the scaffolded supports provided by the researchers and floundered in their progress, yet this did not diminish their self-reported efficacy.

Conversely, the third student did not accurately evaluate her performance while making level 1 , yet her self-efficacy ratings were always high. Sharone consistently reported absolute confidence in her ability to complete tasks successfully regardless of her progress toward her goals. But in fact, she often became stuck in a loop of repeated activity that did not move her progress forward. Because she did not recognize problems with her performance, this suggests that she was also not self-monitoring and self-evaluating. However, researcher feedback during her level 1 interview seemed to shape her self-evaluation of her performance and subsequent self-efficacy ratings began to correspond more accurately with her actual performance.

In each of these instances, students appeared to be inaccurate in the self-efficacy beliefs they held. Mario and Emma maintained strong beliefs that they could accomplish their goals even though their daily performance suggested that they were less able to do so without structured supports to assist. Similarly, prior to researcher feedback during her game interview, Sharone believed she could accomplish her goals even though all evidence indicated that she was off track - for example, she was far behind the other students, she often was not sure of next steps to accomplish, and she was unable to identify when she had skipped critical steps in the process. The corresponding self-regulation failure that occurred is consistent with the literature that indicates that self-efficacy ratings should not be overestimated, but should be fairly accurate and optimistic. Researchers have cautioned that positive links between self-efficacy and desired outcomes (e.g., academic achievement, persistence, cognitive engagement, use of self-regulatory strategies) do not apply for inaccurate self-efficacy beliefs, but rather, self-efficacy beliefs need to be relatively accurate, but optimistic, and calibrated to actual accomplishments (Bandura, 1997; Bembenutty et al., 2013; Pintrich \& Schunk, 2002). Because actual accomplishments play a role in shaping accurate self-efficacy, it is logical that students within the current study who were not able to accurately self-assess deficiencies in their progress also reported over-inflated beliefs about their ability. It is also logical that some students experienced self-regulation failure. Researchers have conjectured that self-regulation failure occurs when students (a) set standards for performance at are too high or too low (i.e., miscalibration), (b) neglect to self-monitor their progress or to inaccurately judge their performance, or (c) do not make changes to adjust behavior based on actual performance (Baumeister \& Heatherton, 1996). Findings from the current investigation support this view.

\subsection{Cost/benefit}

Mario and Emma did demonstrate self-regulatory behaviors throughout the project, but each abandoned these efforts when they perceived the cost to outweigh the benefit. Initially, the idea of creating their own computer games was of high interest to them; however, once they experienced the amount of work that was required to do so, this impeded the motivation of Emma and Mario to create second levels of their games. Thus, when the novelty wore off, the benefit of motivation they had to make a game was not sustained.

Emma and Mario's choice to not use resources for developing their second game level that they viewed as too labor intensive, even while they acknowledged that this work was needed in order for them to succeed, ultimately lead to their complete abandonment of efforts to persist with working on their games. This may have been an indicator of fatigue. Researchers (e.g., Hagger, Wood, Stiff, \& Chatzisarantis, 2010; Mauraven \& Baumeister, 2000; Vohs \& Heatherton, 2000) have previously speculated that the ability to self-regulate is a finite resource that can be depleted and that this fatigue, or ego depletion, can impede both motivation and self-control.

\subsection{Implications for Research and Practice}

Because self-efficacy is considered to play such a critical role in motivating a person's behavior (e.g., DiBenedetto, \& Zimmerman, 2010), these findings are promising. Specifically, findings suggest that teachers can play an important role in helping students improve the accuracy of their self-evaluation of their own performance as a means to improve calibration of student perceptions of their own ability to accomplish a task. This is particularly important when working with students with LD who are often less skilled at self-evaluating their own performance and who often have maladaptive attributions for their performance. More research is needed to better understand whether some types of feedback are more effective than others for assisting accurate student self-evaluation. Research is also needed to better understand the time points where teacher support is especially critical for 
supporting students before self-regulation failure occurs.

More research is needed to better understand how to influence student perceptions of the benefit of effort to self-regulate learning as outweighing the cost of that effort. For students with LD who struggle to learn and who often process information inefficiently, this is both a challenging objective and an important one. Students with LDs that impact their learning are likely to spend more energy than their typically developing peers to accomplish the same task. As such, their likelihood of fatigue and negative peer reference is increased resulting in abandonment of their efforts altogether. The use of highly motivating activities is often employed in classrooms as a means to engage students. However, findings from this study suggest that highly motivating activities alone are not sufficient for sustaining student effort over a prolonged period of time. Findings from the current study are consistent with current thinking that motivation is not stable, but variable depending on context (Linnenbrink \& Pintritch, 2002). This learning context has been described as situational interest where the learner's attention needs to be both caught and held (Mitchell, 1993). While novel activities may serve to initially catch a student's interest and be a motivator for learning, activities that hold student interest may be more important for long lasting effects (Harackiewics, Barron, Tauer, Carter, \& Elliot, 2000). Understanding how to "hold" student interest and mitigate challenges that result in student fatigue are both important areas for future research.

\subsection{Conclusions}

These observations suggest that an intriguing contribution to the further advancement of theories of self-regulation would be to link the desired self-regulatory cycle with overcoming of fatigue or ego depletion conditions. In other words, effort attributions need to be connected with gains in self-efficacy and calibrated with actual accomplishments, but---over time---attributions need to be sufficiently potent to overcome anticipatable fatigue and cost-benefit losses. Such a complex configuration would be predicted to underlie successful learning, and especially involving project-based science learning.

\section{Acknowledgements}

This material is based upon work supported by the National Science Foundation under Grant Number: DRL-1420448. Any opinions, findings, and conclusions or recommendations expressed in this material are those of the author(s) and do not necessarily reflect the views of the National Science Foundation.

\section{References}

Bandura, A. (1993). Perceived self-efficacy in cognitive development and functioning. Educational Psychologist, 28, 117-148. https://doi.org/10.1207/s15326985ep2802_3

Bandura, A. (1997). Self-efficacy: The exercise of control. New York: Freeman.

Baumeister, R. F., \& Heatherton, T. F. (1996). Self-regulation failure: An overview. Psychological inquiry, 7, 1-15. https://doi.org/10.1207/s15327965pli0701_1

Bembenutty, H., Cleary, T. J., \& Kitsantas, A. (Eds.). (2013). Applications of self-regulated learning across diverse disciplines: A tribute to Barry J. Zimmerman. Charlotte, NC: Information Age Publishing.

Bernacki, M. L., Nokes-Malach, T. J., \& Aleven, V. (2015). Examining self-efficacy during learning: Variability and relations to behavior, performance, and learning. Metacognition and Learning, 10, 99-117. https://doi.org/10.1007/s11409-014-9127-x

Borkowski, J. G., Carr, M., Rellinger, E., \& Pressley, M. (1990). Self-regulated cognition: Interdependence of metacognition, attributions, and self-esteem. Dimensions of Thinking and Cognitive Instruction, 1, 53-92.

Carr, M., Borkowski, J. G., \& Maxwell, S. E. (1991). Motivational components of underachievement. Developmental Psychology, 27, 108-118. https://doi.org/10.1037/0012-1649.27.1.108

Chapman, J. W., \& Tunmer, W. E. (2003). Reading difficulties, reading-related self-perceptions, and strategies for overcoming negative self-beliefs. Reading \& Writing Quarterly, 19, 5-24. https://doi.org/10.1080/10573560308205

Cheng, M. T., \& Annetta, L. (2012). Students' learning outcomes and learning experiences through playing a Serious Educational Game. Journal of Biological Education, 46, 203-213. https://doi.org/10.1080/00219266.2012.688848

Connolly, T. M., Boyle, E. A., MacArthur, E., Hainey, T., \& Boyle, J. M. (2012). A systematic literature review of empirical evidence on computer games and serious games. Computers \& Education, 59, 661-686. https://doi.org/10.1016/j.compedu.2012.03.004 
De Corte, E., Mason, L., Depaepe, F., \& Verschaffel, L. (2011). Self-regulation of mathematical knowledge and skills. In Zimmerman, B. J., \& Schunk, D. H. (Eds.), Handbook of self-regulation of learning and performance (pp. 155-172). New York, NY: Routledge.

DiBenedetto, M. K., \& Zimmerman, B. J. (2010). Differences in self-regulatory processes among students studying science: A microanalytic investigation. The International Journal of Educational and Psychological Assessment, 5, 2-24.

Donker, A. S., De Boer, H., Kostons, D., van Ewijk, C. D., \& Van der Werf, M. P. C. (2014). Effectiveness of learning strategy instruction on academic performance: A meta-analysis. Educational Research Review, 11, 1-26. https://doi.org/10.1016/j.edurev.2013.11.002

Giannakos, M. N. (2013). Exploring the video-based learning research: A review of the literature. British Journal of Educational Technology, 44, 191-195. https://doi.org/10.1111/bjet.12070

Graham, S., Harris, K. R., \& Mason, L. (2005). Improving the writing performance, knowledge, and self-efficacy of struggling young writers: The effects of self-regulated strategy development. Contemporary Educational Psychology, 30, 207-241. https://doi.org/10.1016/j.cedpsych.2004.08.001

Guthrie, J. T., Wigfield, A., \& VonSecker, C. (2000). Effects of integrated instruction on motivation and strategy use in reading. Journal of Educational Psychology, 92, 331- 341. https://doi.org/10.1037/0022-0663.92.2.331

Hagger, M. S., Wood, C., Stiff, C., \& Chatzisarantis, N. L. D. (2010). Ego depletion and the strength model of self-control: A meta-analysis. Psychological Bulletin, 136, 495-525. https://doi.org/10.1037/a0019486

Linnenbrink, E. A., \& Pintrich, P. R. (2002). Motivation as an enabler for academic success. School Psychology Review, 31, 313-327.

Linnenbrink, E. A., \& Pintrich, P. R. (2003). The role of self-efficacy beliefs in student engagement and learning in the classroom. Reading \& Writing Quarterly, 19, 119-137. https://doi.org/10.1080/10573560308223

MacGinitie, W. H., MacGinitie, R., Maria, R., \& Dreyer, L. (2000). Gates-MacGinitie Reading Tests. Rolling Meadows, IL: Riverside.

Marino, M. T., Israel, M., Beecher, C. C., \& Basham, J. D. (2013). Students' and teachers' perceptions of using video games to enhance science instruction. Journal of Science Education and Technology, 22, 667-680. https://doi.org/10.1007/s10956-012-9421-9

Mauraven, M., \& Baumeister, R. F. (2000). Self-regulation and depletion of limited resources: Does self-control resemble a muscle? Psychological Bulletin, 126, 247-259. https://doi.org/10.1037//0033-2909.126.2.247

Mitchell, M. (1993). Situational interest: Its multifaceted structure in the secondary school mathematics classroom. Journal of Educational Psychology, 85, 424. https://doi.org/10.1037/0022-0663.85.3.424

Nelson, J. M., \& Manset-Williamson, G. (2006). The impact of explicit, self-regulatory reading comprehension strategy instruction on the reading-specific self-efficacy, attributions, and affect of students with reading disabilities. Learning Disability Quarterly, 29, 213-230. https://doi.org/10.2307/30035507

Pintrich, P. R., \& Schunk, D. (2002). Motivation in education: Theory, research, and Applications (2nd ed.). Upper Saddle, NJ: Prentice-Hall.

Robertson, S. J. (2000). Is attribution training a worthwhile classroom intervention for K-12 students with learning difficulties? Educational Psychology Review, 12, 111-134. https://doi.org/10.1023/A:1009089118008

Schunk, D. H. (1991). Self-efficacy and academic motivation. Educational Psychologist, 26, 207-231. https://doi.org/10.1207/s15326985ep2603\&4_2

Schunk, D. H., \& Zimmerman, B. J. (1997). Social origins of self-regulatory competence. Educational psychologist, 32, 195-208. https://doi.org/10.1207/s15326985ep3204_1

Schunk, D. H., \& Zimmerman, B. J. (2003). Self-regulation and learning. Handbook of psychology. https://doi.org/10.1002/0471264385.wei0704

Shell, D. F., Colvin, C., \& Bruning, R. H. (1995). Self-efficacy, attribution, and outcome expectancy mechanisms in reading and writing achievement: Grade-level and achievement-level differences. Journal of Educational Psychology, 87, 386-398. https://doi.org/10.1037/0022-0663.87.3.386

Tabassam, W., \& Grainger, J. (2002). Self-concept, attributional style and self-efficacy beliefs of students with learning disabilities with and without attention deficit hyperactivity disorder. Learning Disability Quarterly, 
25, 141-151. https://doi.org/10.2307/1511280

Torgesen, J. K., Wagner, R. K., \& Rashotte, C. A. (2012). Test of word reading efficiency (2nd ed.). Austin, TX: PRO-ED Publishing, Inc.

Usher, E. L., \& Pajares, F. (2006). Sources of academic and self-regulatory efficacy beliefs of entering middle school students. Contemporary Educational Psychology, 31, 125-141. https://doi.org/10.1016/j.cedpsych.2005.03.002

Vohs, K. D., \& Heatherton, T. F. (2000). Self-regulatory failure: A resource-depletion approach. Psychological Science, 11, 249-254. https://doi.org/10.1111/1467-9280.00250

Weiner, B. (1985). An attributional theory of achievement motivation and emotion. Psychological Review, 92, 548-573. https://doi.org/10.1037/0033-295X.92.4.548

Yin, R. K. (2014). Case study research: Design and methods. Thousand Oaks, CA: Sage publications.

Zimmerman, B. J. (2000). Self-efficacy: An essential motive to learn. Contemporary Educational Psychology, 25, 82-91. https://doi.org/10.1006/ceps.1999.1016

Zimmerman, B. J., Bandura, A., \& Martinez-Pons, M. (1992). Self-motivation for academic attainment: The role of self-efficacy beliefs and personal goal setting. American Educational Research Journal, 29, 663-676. https://doi.org/10.3102/00028312029003663

\section{Copyrights}

Copyright for this article is retained by the author(s), with first publication rights granted to the journal.

This is an open-access article distributed under the terms and conditions of the Creative Commons Attribution license (http://creativecommons.org/licenses/by/4.0/). 